\title{
Psychological Well-being of Working Women in Malaysia: Married or Single is Better?
}

Nur Salimah binti Alias, Intan Hashimah Mohd Hashim, Mohd Haizzan Yahaya

To Link this Article: http://dx.doi.org/10.6007/IJARBSS/v12-i1/12239

DOI:10.6007/IJARBSS/v12-i1/12239

Received: 12 November 2021, Revised: 17 December 2021, Accepted: 06 January 2022

Published Online: 25 January 2022

In-Text Citation: (Alias et al., 2022)

To Cite this Article: Alias, N. S. binti, Hashim, I. H. M., \& Yahaya, M. H. (2022). Psychological Well-being of Working Women in Malaysia: Married or Single is Better? International Journal of Academic Research in Business and Social Sciences, 12(1), 2501-2511.

\section{Copyright: (c) 2022 The Author(s)}

Published by Human Resource Management Academic Research Society (www.hrmars.com)

This article is published under the Creative Commons Attribution (CC BY 4.0) license. Anyone may reproduce, distribute, translate and create derivative works of this article (for both commercial and non0-commercial purposes), subject to full attribution to the original publication and authors. The full terms of this license may be seen at: http://creativecommons.org/licences/by/4.0/legalcode

Vol. 12, No. 1, 2022, Pg. $2501-2511$

Full Terms \& Conditions of access and use can be found at http://hrmars.com/index.php/pages/detail/publication-ethics 


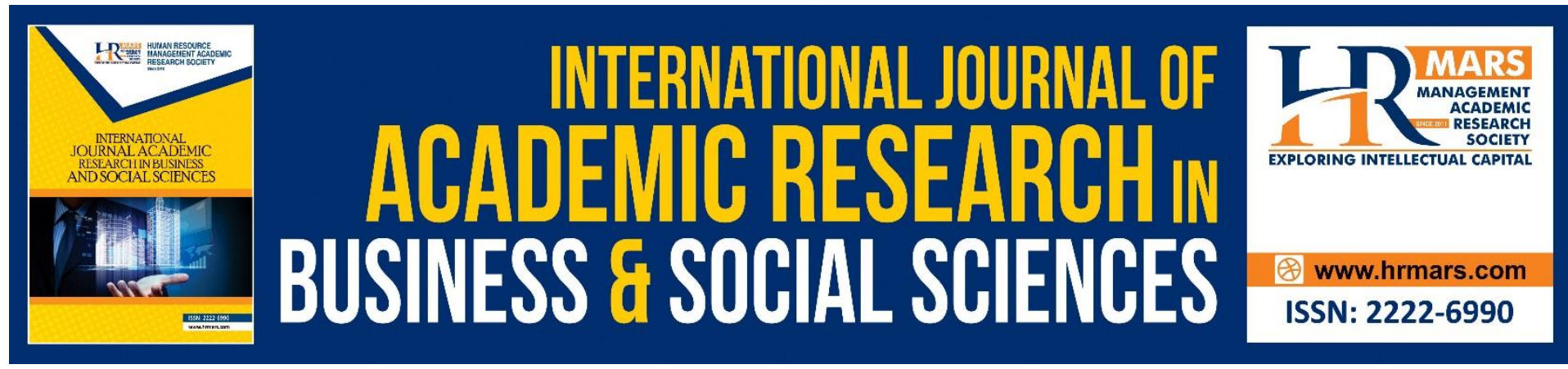

\title{
Psychological Well-being of Working Women in Malaysia: Married or Single is Better?
}

\author{
Nur Salimah binti Alias, Intan Hashimah Mohd Hashim, Mohd \\ Haizzan Yahaya
}

School of Social Sciences, Universiti Sains Malaysia, 11800 Pulau Pinang Malaysia

Corresponding Author Email: salimahalias@student.usm.my

\begin{abstract}
Empowering women's psychological well-being is not about hindering problem for women but to help women becoming someone who can adapt and respond in life's challenges regardless of their marital status. This study aims to compare difference in level of psychological well-being among working women based on their marital status. A survey was conducted to 295 married and 205 single working women from public universities in Malaysia. The Ryff's Psychological well-being scales (42 items) was used as the instrument. The data was analysed using Statistical Package for Social Studies (SPSS) version 23. Findings shows that in general, married working women have better psychological well-being than single working women. The significant difference show in self-acceptance and purpose in life dimensions with single working women score lower than married working. The findings of this study wider perspective of the psychological well-being of women by including factors of marital status to be considered. The results of this study have implications for government in providing a more friendly approach for single community in social and family development. Indirectly, a more balanced approach fosters a healthy community that can help individuals reach their full potential, regardless of marital status.
\end{abstract}

Keywords: Psychological Well-Being, Working Women, Single, Married, Marital Status

\section{Introduction}

Psychological well-being of women is one of scope of well-beings' study that needs to be addressed by the researcher. This is because women played significant roles in country's development. In contradiction with traditional role of women, women nowadays also go to work and not only serve the family at home, hence they also contribute to the nation's economic, social, and political development. In Malaysia, half of women's population is working women (DOSM, 2021). Therefore, more attention is require optimizing their potential to ensure their psychological well-being. One of the aspects is by identifying whether being married or not bring any difference to their psychological well-being. Although many previous studies mostly conclude that married women have better well-being than singles (Dush \& Amato, 2005; Soons \& Liefbroer, 2008; Grover \& Helliwell, 2017), most of the studies have mainly been conducted in western societies and are limited in Malaysia. The lack of studies in Malaysia should not be underestimated as different cultures may provide 
different implications (Diener et al., 2000). In addition, it is undeniable that regardless of marital status, especially working women in Malaysia did experience pressure on their psychological well-being such as for single is facing social stigma in workplace (Hassan \& Velleymalay, 2017) while for married women were related with effects on the well-being in balancing the role between family and works (Noor, 2006; Abdullah et al., 2012; Aziz et al., 2016). However, less visible research was available in comparing women's psychological wellbeing based on the marital status. With the increasing rate of single women and increasing figure of women getting employed in Malaysia (DOSM, 2010), more studies should be done to determine the difference of psychological well-being between single and married working women.

\section{Literature Review}

Based on Ryff's model of psychological well-being (Ryff, 1989; 2014; Ryff \& Singer, 1996) women with good psychological well-being (PWB) interprets as when the women are be able to appreciate who they are, have a good and meaningful relation with other, can make their own decision, be able to control situation of crisis and opportunity, know what they want in life and have the feeling that they are improving and developing.

The concept of PWB is constructed based on the context of a eudaimonic perspective that disputes pleasure or happiness as a key principle in well-being (Ryff, 1989; Ryan \& Deci, 2001). Eudaimonic perspective argues that people report happiness do not always imply that they are psychologically well or feeling positive or satisfied (Waterman, 1993). Furthermore, the eudaimonic view focuses on living well and realising one's potentials, which, when combined with the concept of psychological well-being, describes well-being as a process of realising one's true self and fully engaging with the genuine self in experiencing life rather than an outcome. (Deci \& Ryan, 2008).

Starting with the basis of condemning the way well-being is measured in subjective wellbeing, Ryff (1989) suggested psychological well-being could be represent in a model consisting of six components. The six components are self-acceptance; a positive assessment of oneself and one's past, environmental mastery; a sense of continuing growth and development as a person, purpose in life; the belief that one's life is purposeful, positive relation with others; quality relationships with others, autonomy; the ability to effectively manage one's life and surrounding world, and personal growth; a sense of self-expansion (Ryff \& Keyes, 1995; Ryff \& Singer, 2008).

Therefore, the PWB concept encompasses not only positive emotions such as happiness and satisfaction, but also when a person functions psychologically effectively, which includes the development of one's potential, having control over one's life, having a sense of purpose in life, and having positive relationships. PWB also emphasises that good PWB does not imply that people will always feel happy, but that recognising painful emotional experiences as a natural part of life and being able to handle these negative or unpleasant feelings is importance for long-term happiness. Dealing with a problem, despite its unpleasantness, contributes to a sense of autonomy and sense of achievement of a meaningful purpose in life, both of which are beneficial to a person's well-being.

Psychological well-being may be differentiate based on marital status as different status experience different challenges to their well-being. Challenges of being single women in Malaysia were more distinct compared to western countries delayed marriage is still an uncommon norm (Jones, 2010) which impacted by strong traditional-religion marriage belief among Malaysian (Azmawati et al., 2015). Among the challenges were stigmatization and 
discrimination formed by society due to being single (Ibrahim \& Han, 2009; Faudziah \& Mustafar, 2017; Saili \& Saili, 2018; Alwi \& Lourdunathan, 2020). Faudziah \& Mustafar, (2017) concluded based on their review on the effects of stigma to single women found that stigmatization such as negative labelling and attitudes were common in Malay society and has caused single women to experience stress and emotional disturbance.

(Ibrahim \& Hassan, 2009) conducted an interview with three professional women and found that stigmatization was related with negative labels to the single women such as "andartu" and "tak laku". In line with the study, Saili \& Saili (2018) confirmed that most of the women encounter stigmatization of negative impression and single woman also reported being discriminate in a way they were treated in less advantageous manner compared to married women. This situation also occurred in family and public. Single women in Malaysia consider their difficulties as a result of judgmental attitudes of people towards singles; struggle accepting who they are; being stereotyped and treated unfairly; feelings of insecurity and displacements; and experience of negative emotion (Alwi \& Lourdunathan, 2020).

Unlike single women who experienced pressure from social stigmatization and discrimination because of not being married, the challenges of married women well-being often acknowledged in many established literatures were related with multiple roles challenges. The challenges of multiple roles among married women were often related with their conflict in balancing between role in family and as a worker. There was a significant relationship found between work-family conflict, personal burnout, and distress symptoms (Noor, 2006). According to Ibrahim et al. (2009), work-family conflict was the key issue influencing employee well-being in South-East Asian countries, due to changing workforce demographics and increased female participation.

\section{Research Objective}

The research objective is as follow

- To compare the level of psychological well-being between single and married working women in Malaysia.

\section{Method}

This study used quantitative survey methods to collect and to analyse numerical data to answer the research questions. Survey is one of the strategies used in quantitative studies to collect information from people to describe, compare, or explain their knowledge, attitudes, and behavior (Fink, 2003). It provides a quantitative or numeric description of trends or opinions of a population by studying the sample (Creswell, 2009). The survey approach was chosen because it allowed the researcher to draw conclusions about the characteristics of the target group by extrapolating from the study's measurement data. In addition, the survey employed in this study was cross-section and the data were collected using online selfadministered questionnaires in the form of Google forms.

\section{Population}

The focus of this study was working women in Malaysia. They represent 6.1 million members of the Malaysian population (DOSM, 2019). Due to cost and time constraints, it was not possible to use the total number of working women as the population. To address this issue, the approach focused on working women in specific organizations. Thus, population involved in this research refers to women who work in public universities in Malaysia. The rationale for selecting this group as the study's population was based on two reasons. First, public 
universities are locations that have three sectors that have highest percentages of women involved as a workforce (KRI, 2018) which are sectors of professional, service, and clerical sectors. Second, public universities were chosen to maintain the homogeneity of public workers or government servants, since the public and private sectors are so dissimilar in many ways. In 2019, the total recorded number of Malaysian women academic staff therein was 17,335 (Ministry of Education (MOE), 2019).

\section{Sample Size}

The researcher chose nine public universities out of twenty public universities in Malaysia based on a multi-stage cluster sampling. The nine universities are Universiti Sains Malaysia (USM), Univeristi Teknologi Malaysia (UTM), Universiti Utara Malaysia (UUM),Universiti Pendidikan Sultan Idris (UPSI) Universiti Teknikal Malaysia Melaka (UteM), Universiti Malaysia Perlis (UniMAP), Universiti Malaysia Pahang (UMP), Universti Teknologi Mara (UiTM) and Universiti Malaysia Sabah (UMS). Total samples needed for the research were decided based on the table of sample size by Krejcie and Morgan (1970) for a population of 15,000 and an unknown large population. In addition, the determination of the sample size for this study also followed the formula developed by (Cochran, 1977). The researcher needed only 375 to 385 respondents. In this study, the researcher obtained 500 qualified respondents, which was more than required. A larger sample size is beneficial because it minimises the gap between the sample and the population, which helps to reduce sampling errors and better represents the population (Zainudin, 2010).

\section{Research Instruments}

One of the most often used measures to measure psychological well-being is Ryff's psychological well-being scale. There were several versions of this scale, including 84-item, 42-item, and 18-item versions. This study used the 42-item scale to measure psychological well-being based on six identified components labelled as: (1) self-acceptance, (2) environmental mastery, (3) personal growth, (4) positive relations with others, (5) purpose in life, and (6) autonomy. The psychometric properties of Ryff's model have been revisited multiple times (Ryff \& Keyes, 1995; Ryff \& Singer, 1996). It has proven to be a good measurement of well-being in various scientific disciplines and in clinical practice (Ryff, 2014). Each factor consisted of seven items. Each item contained a statement such as, "In general, I feel I am in charge of the situation in which I live", to which the respondents were asked to rate their level of agreement to the statement based on a six-point Likert scale (1=strongly disagree, 2=somewhat disagree, 3=disagree slightly, 4=agree slightly, 5=somewhat disagree, and $6=$ strongly agree).

To eliminate biases in measuring the psychological construct, the Ryff scale has 20 positive and 22 negative items. Negatively phrased items were scored in the opposite direction, with higher values indicating greater well-being. If a circled score is 6 , the adjusted score is 1 . The totals for answers in each of the six dimensions were then added together. Generally, high scores mean greater psychological well-being. However, three levels of psychological wellbeing have been established based on calculation of mean scores suggested by (Schweigert, 1994) to interpret the score hence represent an individual's psychological well-being condition. Therefore, as seen in table 1, there are three levels of psychological well- being: high, moderate, and low based on the range of mean score. 


\begin{tabular}{ll}
\hline Mean score range & Level of psychological well-being \\
\hline $1.00-2.66$ & Low \\
$2.67-4.33$ & Moderate \\
$4.34-6.00$ & High \\
\hline
\end{tabular}

\section{Data Analysis}

Using a statistical test, the data from the questionnaire was numerically scored and quantified. Descriptive analysis was utilized to describe the demographic profiles of the respondents and to measure the level of psychological well-being. The data were generated by using SPSS version 23 and the results were presented in the form of mean level, frequency, and percentage. This study also performed an independent sample $t$-test through SPSS to determine the differences of psychological well-being and its dimensions experienced by the respondent with different marital status. Effect size was also calculated to determine the size of differences between the groups. According to Cohen, (1992), value of 0.2 is interpret as small effect, while 0.5 is medium and 0.8 is large effect. The effect size (d) for independent sample t-test can be calculated by dividing the mean difference between the groups by the pooled standard deviation as shown in the formula below.

$\mathrm{d}=(\mathrm{M} 2-\mathrm{M} 1) / \mathrm{SD}$ pooled

$M 2 \& M 1=$ The value of mean for group 2 and 1 respectively

SD pooled $=$ An estimator of the pooled standard deviation of the two groups, SD pooled can

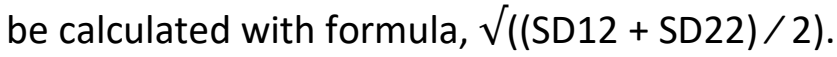

\section{Findings}

\section{Profile of the respondents}

The profile of the respondents are 295 (59\%) respondents out of 500 respondents are married women and only $205(41 \%)$ are single women. Most of this woman in the study was in the age range within the age of 31 to 40 years old, with total number of 252 respondents $(50.4 \%)$. 457 respondents are Malay (91.4\%). Most of the respondents are academician with total number of respondents were $350(70 \%)$ respondents. Then, majority of the respondents have been working within the range of 11 to 15 years (122 respondents, 24.4\%). In term of level education, majority of the respondents in this study is a PhD holder with total 223 number of respondents, accounted for $44.6 \%$ of the entire study sample.

\section{Results}

The conducted t-test analysis on psychological well-being was found to be statically significant $t(498)=-2.29, p<.05 ; d=0.2$. However, only dimension of self-acceptance $t(498)=3.52, p$ $<.001 ; d=0.32$ and purpose in life $t(498)=3.58, p<.001 ; d=0.33$ differences were found to be statically significant. While other dimensions were found to be non-significant. The effect size of self-acceptance was $d=0.32$ and purpose in life was $d=0.33$, both were in the range of small effect (Cohen, 1992). Even so, these results indicate that individuals in married group ( $M=4.67, S D$ 0.49) had better psychological well-being particularly in dimensions of selfacceptance ( $M=4.74, S D 0.70$ ) and purpose in life ( $M=4.88, S D 0.56)$ than individuals in single group $(M=4.56, S D 0.58),(M=4.51, S D=0.76)$ and $(M=4.67, S D 0.71)$ respectively. The summary of the results shown in table 3 below: 


\begin{tabular}{llllllll}
\hline $\begin{array}{l}\text { Variables } \\
\text { Dimensions }\end{array}$ & Married & & Single & & $\begin{array}{l}\text { t-Test } \\
(\mathrm{t})\end{array}$ & $\begin{array}{l}\text { Sig. } \\
(\mathrm{p})\end{array}$ & $\begin{array}{l}\text { Effect } \\
\text { size }(\mathrm{d})\end{array}$ \\
& Mean & SD & Mean & SD & & & \\
\hline $\begin{array}{l}\text { Psychological well- } \\
\text { being }\end{array}$ & 4.67 & 0.49 & 4.56 & 0.58 & -2.29 & $0.022^{* *}$ & 0.20 \\
Self-acceptance & 4.74 & 0.70 & 4.51 & 0.76 & 3.52 & $0.00^{*}$ & 0.32 \\
$\begin{array}{l}\text { Purpose in Life } \\
\text { Personal Growth }\end{array}$ & 4.88 & 0.56 & 4.67 & 0.71 & 3.58 & $0.00^{*}$ & 0.33 \\
$\begin{array}{l}\text { Autonomy } \\
\text { Environmental }\end{array}$ & 4.05 & 0.63 & 4.95 & 0.65 & 0.89 & 0.37 & - \\
$\begin{array}{l}\text { Mastery } \\
\text { Positive Relation }\end{array}$ & 4.70 & 0.68 & 4.09 & 0.78 & -0.62 & 0.54 & - \\
\hline
\end{tabular}

\section{Discussions}

The result of this study found that married women recorded higher mean scores of psychological well-being compared to single women. This finding is consistent with the finding by Soons et al (2009) proved that any move toward a more committed partnership was found to be beneficial and increase individual's well-being because of being in relationship means more resources and lessening an uncertainty. Similar results were discovered in Grover \& Helliwell's (2017) study, which demonstrated that throughout all phases of marriage, married people's well-being was still better than unmarried people's, implying that the benefits of well-being were more apparent to married people than unmarried people. In addition, married young adults were found more satisfied with their lives and have lesser distress level compared to unmarried young adults (Uecker, 2012). In Malaysia, based on Fifth Malaysian Population and family survey, married women reported were better in well-being compared to single women, they were reported had better standard of living and religious practices (Abdul Razak et al., 2019).

In addition, it might be because of the marriage belief held by Malaysian on single women where single women facing stigma such as 'anak dara tua' or there was something wrong if women not getting married at certain age, which might cause them to feel unaccepted because of their single status. This assumption is in line with finding reported by Faudziah \& Mustafar (2017) indicated that stigmatization had pressure on unmarried women cause. Particularly for single and career women, they were more possible to face the stigmatization from colleagues (Hassan \& Velleymalay, 2017). Therefore, it may explain the reason single women in this study who were career women to be reported to had lower level of well-being than married women.

Interestingly, the findings of the study found only dimensions purpose in life and selfacceptance were statically different significantly. The finding of this study gives the impression that single women in this study felt they do not have clear purpose in life compared to married women and had a greater annoyance of accepting themselves than married women. The findings are partially consistent with Hsu \& Barrett (2020) who found evidence indicated unmarried report to have lower purpose in life compared with the married.

The linked between those two dimensions that influenced by the marital status could be connected if marriage is seen as a transition of life. Individuals who were succeeded to enter the stage of marriage seem to have clear purpose of life as now they can move on to another stages like parenthood. According to Soons et al (2009), due to married women are more 
socially connected and legally approved to obtain social benefits such as parental or residential meetings, they were more clear than single women about what role she should present herself in the community which may aid married women in regaining their feeling of purpose and self-acceptance.

While, as marriage is treated as transition in life single women perceived unmarried status as a temporary stage and, somehow looked marriage as a thing that ought to be achieved. This speculation is consistent with findings reported by Sandfield \& Percy (2003), women view their single status as a temporary stage in their lives, and they need to prepare for marriage. They also believe that remaining single later in life poses a threat because it is thought to make women feel lonely and alienated. Furthermore, singlehood might make women feel ambivalent about their current life path and ambiguous regarding the reason for their singleness (Lewis \& Moon, 1997). This feeling may become a reason for them to felt something is not right and blame themselves thus contributed to the low score in selfacceptance.

\section{Conclusions}

In general, married women had better level of psychological well-being than single women, the different were found at self-acceptance and purpose in life dimensions. Supported with previous literatures, single women have score lower in psychological well-being than married women were related with the uncertain support and resources received by singles. In addition, women's perception toward marriage may also be the reason of lower score in dimensions of purpose in life and self-acceptance. Future studies should compare factors influences psychological well-being based on marital status on different kind of social supports and individual's belief in Malaysian context.

\section{Implications}

The findings of the study that reported single working women had a lower sense of purpose in life and self-acceptance than married working women are new findings in the literature of working women's psychological well-being in Malaysia which contribute to the development of the literature. In addition, the findings may give the government additional insight into how they can approach society development, particularly for the single community. A balanced strategy that emphasises family development while also offering a community that is welcoming to single people can assist to modify people's ideas of marriage, which most people regard as a goal rather than an option. Indirectly, a more balanced approach fosters a healthy community that can help individuals reach their full potential, regardless of marital status. It might stress the value of having a good purpose in life and being self-assured, both of which help people make decisions based on their desires.

\section{References}

(KRI), K. R. I. (2018). The state of households 2018: Different realities (3rd Edition (ed.)). Khazanah Research Institute.

Abdul Razak, A. R., Mahpul, I. N., \& Aziz, A. (2019). Women subjective well-Being in Malaysia: Findings from fifth malaysian population and family survey (MPFS-5). International Journal for Studies on Children, Women, Elderly And Disabled, 8(October), 61-72. http://familyrepository.Ippkn.gov.my/779/1/Women Subjective Well-Being in Malaysia Findings from MPFS 5.pdf

Abdullah, N. H., Wahab, E., Shamsuddin, A., \& Noor, H. M. (2012). Perceptions on career 
barriers among working women. OIDA International Journal of Sustainable Development, $4(7), 93-100$.

Alwi, A. H., \& Lourdunathan, P. (2020). Challenges and well-being of single women living in Malaysia. Journal of Behavioral Science, 15(1), 1-18.

Aziz, N. N. A., Abu Yazid, Z. N., Tarmuji, N. H., \& Samsudin, M. A. (2016). The fourfold taxonomy of work-family balance and well-being: The moderating effect of coping strategy. $E$ Academia Journal UiTMT, 5(1), 1-12.

Azmawati, A. A., Hashim, I. H. M., \& Endut, N. (2015). "Don't marry, be happy!" - how single women in Malaysia view marriage. SHS Web of Conferences, 18(2004), 03001. https://doi.org/10.1051/shsconf/20151803001

Cochran, W. G. (1977). Stratified Random Sampling, Further Aspects of Stratified Sampling. In Sampling https://archive.org/details/Cochran1977SamplingTechniques_201703/page/n7

Cohen, J. (1992). A Power Primer. Psychological Bulletin, 112(1), 155-159. https://doi.org/10.1038/141613a0

Creswell, J. W. (2009). Research design: Qualitative, quantitative and mixed methods approaches (3rd ed.). SAGE Publications, Inc.

Deci, E. L., \& Ryan, R. M. (2008). Hedonia, eudaimonia, and well-being: An introduction. Journal of Happiness Studies, 9(1), 1-11. https://doi.org/10.1007/s10902-006-9018-1

Diener, E. D., Gohm, C. L., Suh, E., \& Oishi, S. (2000). Marital Status and subjective well-being across cultures. Journal of Cross-Cultural Psychology, 31(4), 419-436.

DOSM, D. S. M. (2010). Population distribution and basic demographic characteristics 2010. Department of Statistics Malaysia. https://www.mycensus.gov.my/index.php/censusproduct/publication/census-2010/659-population-distribution-and-basic-demographiccharacteristics-2010

DOSM, D. S. M. (2019). Labour force survey report, Malaysia, 2019. Department of Statistics Malaysia.

DOSM, D. S. M. (2021). Statistics on women empowerment in selected domains, Malaysia, 2021. Department of Statistics Malaysia, 1-5.

Dush, C. M. K., \& Amato, P. R. (2005). Consequences of relationship status and quality for subjective well-being. Journal of Social and Personal Relationships, 22(5), 607-627. https://doi.org/10.1177/0265407505056438

Faudziah, Y., \& Mustafar, F. W. (2017). Cabaran bujang lewat usia: Stigma terhadap wanita berkerjaya. Jurnal Sains Sosial, 2, 117-129.

Fink, A. (2003). The survey handbook (2nd ed.). SAGE Publications, Inc. https://doi.org/https://dx.doi.org/10.4135/9781412986328

Grover, S., \& Helliwell, J. F. (2017). How's life at home? New evidence on marriage and the set point for happiness. In Journal of Happiness Studies.

https://doi.org/10.1007/s10902-017-9941-3

Hassan, N. A., \& Velleymalay, S. K. (2017). Wanita bekerja dan kahwin lewat : Satu kajian. Journal of Social Sciences and Humanities, 15(5), 128-144.

Hsu, T., \& Barrett, A. E. (2020). The association between marital status and psychological wellbeing : Variation across negative and positive dimensions. Journal of Family Issues, 1-24. https://doi.org/10.1177/0192513X20910184

Ibrahim, R., \& Hassan, Z. (2009). Understanding singlehood from the experiences of nevermarried malaymuslim women in Malaysia: Some preliminary findings. European Journal of Social Sciences, 8(3), 395-405. 
Jones, G. W. (2010). Changing marriage patterns in Asia. In ARI Working Paper,Series No. 131. https://doi.org/10.4324/9781315148458

Krejcie, R. V., \& Morgan, D. W. (1970). Determining Sample Size for Research Activities. Educational and Psychological Measurement, 30, 607-610.

Lewis, K. G., \& Moon, S. (1997). Always single and single again women: A qualitative study. Journal of Marital and Family Therapy. https://doi.org/10.1111/j.17520606.1997.tb00238.x

Ministry of Education (MOE). (2019). Statistik pendidikan tinggi 2019: Kementerian Pengajian tinggi.

Noor, N. M. (2006). Malaysian women's state of well-being: Empirical validation of a conceptual model. Journal of Social Psychology, 146(1), 95-115.

https://doi.org/10.3200/SOCP.146.1.95-115

Ryan, R. M., \& Deci, E. L. (2001). On happiness and human potentials: A review of research on hedonic and eudaimonic well-being. Annual Review of Psychology, 52, 141-166. https://doi.org/10.1146/annurev.psych.52.1.141

Ryff, C. D. (1989). Happiness is everything, or is it? Explorations on the meaning of psychological well-being. Journal of Personality and Social Psychology, 57(6), 1069-1081. https://doi.org/10.1037/0022-3514.57.6.1069

Ryff, C. D. (2014). Psychological well-being revisited: Advances in the science and practice of eudaimonia. Psychotherapy and Psychosomatics, 83(1), 10-28. https://doi.org/10.1159/000353263

Ryff, C. D., \& Keyes, C. L. M. (1995). The structure of psychological well-Being revisited. Journal of Personality and Social Psychology, 69(4), 719-727. https://doi.org/10.1037/00223514.69.4.719

Ryff, C. D., \& Singer, B. (1996). Psychological well-being: Meaning, measurement, and implications for psychotherapy research. Psychotherapy and Psychosomatics, 65(1), 1423. https://doi.org/10.1159/000289026

Ryff, C. D., \& Singer, B. H. (2008). Know thyself and become what you are: A eudaimonic approach to psychological well-being. Journal of Happiness Studies, 9(1), 13-39. https://doi.org/10.1007/s10902-006-9019-0

Saili, J., \& Saili, A. R. (2018). At odds: Perceived stigma of single professional Malay women. International Journal of Academic Research in Business and Social Sciences, 8(14), 79-90.

Sandfield, A., \& Percy, C. (2003). Accounting for single status: Heterosexism and ageism in heterosexual women's talk about marriage. Feminism and Psychology, 13(4), 475-488. https://doi.org/10.1177/09593535030134013

Schweigert, W. (1994). Research methods \& statistics for psychology. Brooks/Cole.

Soons, J. P. M., \& Liefbroer, A. C. (2008). Together is better? Effects of relationship status and resources on young adults' well-being. Journal of Social and Personal Relationships, 25(4), 603-624. https://doi.org/10.1177/0265407508093789

Soons, J. P. M., Liefbroer, A. C., \& Kalmijn, M. (2009). The long-term consequences of relationship formation for subjective well-being. Journal of Marriage and Family, 71(5), 1254-1270. https://doi.org/10.1111/j.1741-3737.2009.00667.x

Uecker, J. E. (2012). Marriage and mental health among young adults. Journal of Health and Social Behavior, 53(1), 67-83. https://doi.org/10.1177/0022146511419206

Waterman, A. S. (1993). Two conceptions of happiness: Contrasts of personal expressiveness (eudaimonia) and hedonic enjoyment. Journal of Personality and Social Psychology, 64(4), 678-691. https://doi.org/10.1037/0022-3514.64.4.678 
INTERNATIONAL JOURNAL OF ACADEMIC RESEARCH IN BUSINESS AND SOCIAL SCIENCES

Vol. 12, No. 1, 2022, E-ISSN: 2222-6990 @ 2022 HRMARS

Zainudin, H. A. (2010). Research Methodology for Business and Social Science. University Publication Centre (UPENA), UiTM. 